\title{
Effect of A Nursing Care protocol on the Duration of Hospitalization of Children with Pneumonia
}

\author{
Nagwa A. Zain ELdin ${ }^{1}$, Taghreed K. Omar ${ }^{2}$, Hanaa M. Ahmed ${ }^{3}$ and Lamiaa \\ A., Kamar $^{4}$ \\ ${ }^{1}$ Professor of pediatric Nursing,${ }^{2}$ Assistant Professor of pediatric Nursing,${ }^{3}$ Lecturer of \\ Pediatric Nursing, Faculty of Nursing, Menoufia University, ${ }^{4}$ Nursing Supervisor at ministry \\ of Health
}

\begin{abstract}
Pneumonia is the leading cause of death, killing up to five million under five years age annually in developing countries. Therefore, the purpose of this study was to assess the effect of a nursing care protocol on the duration of hospitalization of children with pneumonia. A quasi-expermintal design was used. The study was conducted in the Pediatric Intensive Care Unit and Medical Word at Meet Khalaf Chest Hospital, Shebin El-Kom city. A convenient sample of 40 nurses in the above mentioned setting was included. Two instruments were used for data collection. A structured interview questionnaire and an observational checklist were used. Results revealed that nurses gained more knowledge and better practices on posttest $(80.55 \pm 3.1)$ than on pretest $(64.07 \pm 5.97)$. Also, there was a positive correlation between nurses knowledge, practices and duration of hospitalization. As well as the duration of hospitalization of children with pneumonia was reduced after implementation of the nursing care protocol $(1,900 \pm .900) \mathrm{Vs}(3.67 \pm .572)$. It was concluded that, the period of hospitalization of children with pneumonia was reduced following the application of the nursing care protocol. Therefore, it was recommended that the nursing care protocol for pneumonia should be available for all nurses and should be a part of their contining nursing education to ensure the provision of high quality of nursing care and lower length of hospitalization.
\end{abstract}

Keywords: Pneumonia, Nursing care protocol, Duration of hospitalization.

\section{Introduction}

Pneumonia is the leading cause of morbidity and mortality in children worldwide especially in the developed countries. Nearly 40.000 to 70.000 of children die each year in The United States because of pneumonia (Suliadi et al., 2017). The incidence of childhood pneumonia in children under five years is about 156 million episodes each year worldwide, approximately 151 of them are in the developing countries (WHO, 2014).

In Egypt the mortality rate of pneumonia in children under five years ranges from 70-100 per 1000 live birth (Abd El-Sattar et al., 2017). World health Organization (WHO) classified pneumonia according to its severity with little or no access to diagnostic technology; the classifications determined the appropriate case management actions. In developing countries the assessment of children is based on the clinical signs alone (WHO, 2014).

Serious preventive measures should be taken by pediatric nurse in order to avoid more prevalence of pneumonia and to decrease length of hospital stay (Rylance, 2016).American Lung Association (ALA) developed pneumonia control strategy suitable for countries with limited resources and constrained health system. It consists of classifying the severity of illness using simple clinical signs such as fast breathing, chest in drawing and general danger signs (ALA, 2016). Pneumonia requires nursing care protocols that focus on close 


\section{Effect of A Nursing Care protocol on the Duration of Hospitalization of Children with \\ Pneumonia}

monitoring and active therapeutic intervention. Therefore, the nursing care should focus on monitoring of the child respiratory status, providing adequate rest, maintaining patent airway, ease respiratory efforts, controlling fever, prevent dehydration, provide nutrition, skin care, mouth care, administer medication, perform chest physiotherapy, provide oxygenation, assist in diagnostic measures, ensuring psychological support for children and their parents then preventing complications (Kyle, 2015).

Pneumonia is a major health problem affecting most children under five years age. The incidence at Meat Khalaf Chest Hospital was 158 hospitalized cases with pneumonia last year. Meat Khalaf chest hospital provide health care services for most of Menoufia villages. So, it is good chance to provide nurses with a designed nursing care protocol for pneumonic children in order to improve their knowledge and practices as well as decrease children length of hospital stay.

\section{Purpose}

The purpose of the study to assess the effect of a nursing care protocol on the duration of hospitalization of children with pneumonia.

\section{Research hypotheses}

1- Nurses who receive health education about the nursing care protocol higher knowledge and practice score on post test than pretest..

2- Implementation of the nursing care protocol will lead to reduction of the period of hospitalization of children on post test than pretest.

Definition of nursing care protocol

It is a specific written procedure that prescribes nursing actions in a given situation. Health agencies and physicians establish protocols to ensure consistency and quality of care.( medical dictionary ).

In this study, it includes patient's assessment (e.g., age, sex, length of child hospital stay), methods of administering specific medications (Oral medication, intramuscular injection, intravenous injection). Special-care modalities for patients (Pulse and respiration variation arterial blood gases oxygen therapy mechanical ventilation suctioning endotracheal tube postural drainage). It will be assessed using instruments developed by Center for Disease Control and Prevention (CDCP, 2014) and an observational checklist developed by Labeau (2007)

\section{Methods}

Research design: A quasi experimental design was utilized (pre, and post test).

Research setting: This study was conducted in the Pediatric Intensive Care Unit and Pediatrics word at Meet Khalaf Chest Hospital in Shebin El kom City.

Sampling: A convenient sample of 40 nurses (13 from PICU \& 27 from medical ward) who were caring for children with pneumonia were included. All hospitalized children diagnosed with pneumonia during the period of data collection were involved in this study.

\section{Exclusion criteria for children:}

Children with any other chronic diseases were excluded because they were expected to have longer hospitalization.

Instruments: two instruments were utilized for data collection.

Instrument one: A structured interview questionnaire. It was developed by the Center for Disease Control and 
Prevention (CDCP, 2014) and adopted by the researcher to assess nurse's knowledge about pneumonia. It consisted of two parts:

- Part one: Characteristics of the studied nurses such as age, level of education and years of experience.

- Part two: Nurses knowledge about pneumonia. It contains multiple choice questions about pneumonia such as definition, causes, signs and symptoms, types of infection, dangerous signs, prevention, diagnosis, standard case management, weighing, dehydration prevention, principles of documentation and preparation for discharge.

\section{Scoring system for nurse's knowledge}

\begin{tabular}{|l|c|}
\hline Complete knowledge & $>80 \%$ \\
\hline Incomplete knowledge & $60-80 \%$ \\
\hline Do not know & $<60 \%$ \\
\hline
\end{tabular}

Instrument two: Observational
checklist. It was developed by Labeau (2007) and modified by the researcher to assess nurse's adherence to the protocol of care for children with pneumonia. The researcher observed nurses while caring for children with pneumonia and fulfilled the checklist. It consisted of two parts.

Part one: Characteristics of the studied children such as age, sex, classification of children and length of hospital stay.

Part two: Nurses practices about care of children havng pneumonia such as promoting rest, control of fever, wash hand, mouth care, oral medication, intramuscular and intravenous injection, measuring vital signs (temperature, pulse, respiration), feeding (nasogastric, bottle feeding), oxygen therapy, mechanical ventilation, suctioning (nasal, oral and endotracheal), postural drainage, assist in diagnostic measures, psychological support (child and parent) and preparation for discharge.

\section{Scoring system for each item.}

\begin{tabular}{|c|c|c|}
\hline Items & Score & $\begin{array}{c}\text { Total } \\
\text { Score }\end{array}$ \\
\hline Adequately done & 2 & $>80 \%$ \\
\hline Inadequately done & 1 & $60-80 \%$ \\
\hline Not done & 0 & $<60 \%$ \\
\hline
\end{tabular}

\section{Validity}

For validity assurance, the two instruments were submitted to a jury of five experts in the pediatrics field (two professor, two assistant professor in the pediatric nursing and one professor in the pediatrics medicine). Content validity was assessed using content validity index average(S-CVI AAVE). The lower limit of acceptability for S-CVIAAVE was 0.80 .

\section{Reliability}

Internal consistency of the items was evaluated using Cronbach's alpha efficiency $(\mathrm{a} \geq 0.85)$.

\section{Ethical consideration}

- A written consent was obtained from nurses who participated in the study.

- Confidentiality and anonymity of nurses' data were assured through coding all data and put all paper in a closed cabinet.

\section{Pilot study}

Pilot study was carried out on $10 \%$ (5 nurses) of the sample to test the practicability, applicability, consistency, clarity and feasibility of the study instruments to estimate the 


\section{Effect of A Nursing Care protocol on the Duration of Hospitalization of Children with \\ Pneumonia}

needed time to fill them. No modifications were done.

\section{Procedure}

1- An official permission to carry out the study was obtained from the director of the setting after submitting an official letter from the Dean of the Faculty of Nursing explaining the purpose of the study and the method of data collection. A meeting was conducted with the director of the setting to obtain a permission for conducting the research, explain the purpose and expected outcomes.

2- Data was collected over a period of six months. It started from October 2016 until March 2017, the researcher introduced herself to the nurses before starting the program Assessment of children length of hospitalization was done one month before starting the protocol of care using the hospital records (pretest), Assessment of nurses' knowledge were done at the beginning of the study and lasted for 15 days (pretest), knowledge deficit areas were identified for all nurses. Nurses' practice was assessed by observing nurses' while caring for children with pneumonia (pretest). Observation was carried out four days per week during the morning and afternoon shifts and it lasted for three hours to cover all items of the observation checklist. Nurses weren't informed that they would be observed and areas of weakness in nurses' practices were identified and protocol of care was set.

3- The protocol was planned to be provided in three sessions (one session for knowledge and two sessions for practice). The first session aimed to provide nurses' with knowledge about pneumonia (theoretical part). The second two sessions aimed to improve nurses' practices about care of children with pneumonia (practical part).

4- Nurses were divided into five small groups. Each group contains 8 nurses. Each group received three sessions (1 theoretical and 2 practical). The first session was about general knowledge of pneumonia such as definition, causes, signs and symptoms, types of infection, dangerous signs, prevention, diagnosis, standard case management, weighing, dehydration prevention, principles of documentation and preparation for discharge (theoretical part). Lectures, printed material, illustrated pictures and group discussion were used. A booklet was provided for each nurse. The theoretical part took place in a room inside each unit. The session lasted for two hours and each nurse had the opportunity to ask questions. The second session was about general nursing care of pneumonia such as promotion of rest, control of fever, wash hands, mouth care, administration of medications, measuring vital signs and feeding (practical part).The third session was about specific nursing care of pneumonia such as oxygen therapy, mechanical ventilation, suctioning, postural drainage, assist in diagnostic measures, psychological support and preparation for discharge (practical part). Demonstration was provided by the researcher in the real clinical setting and time was allowed for each nurse to re-demonstrate the procedures under supervision until feel competent. Each session lasted for 3 hours. Direct reinforcement in the form of material reward as well as affection and encouragement was provided as a positive feedback.

5- Nurse's knowledge, practice and length of hospital stay were 


\section{Effect of A Nursing Care protocol on the Duration of Hospitalization of Children with \\ Pneumonia}

reassessed immediately after implementation of the nursing care protocol using the same form of the instrument (posttest). Reassessment for the retention of knowledge and practice was carried out three months later (follow-up).

\section{Data analysis}

Data was coded and transformed into specially designed form to be suitable for computer data entry process. Data was entered and analyzed by using SPSS (Statistical Package for Social Science) statistical package version 21. Graphics were done using Excel program. Quantitative data were presented by mean (X) and standard deviation (SD). ANOVA test for the analysis of variance was used. Qualitative data was presented in the form of frequency distribution tables, number and percentage. It was analyzed by chi-square test. Level of significance was set if $P$ value $\leq 0.05$ for all statistical tests (Morton et al., 2001).

\section{Results}

Table1.illustrated distribution of studied nurses and children according their characteristics. It was found that approximately less than half of the studied nurses aged ranged from 25-30 years old and more than one third were bachelor and diploma degree $(37.5 \%)$. Also, about one third of them have 1-3 years of experience. In relation to classifications of children with pneumonia, it was found that three quarter of studied children have severe pneumonia.

Tables 2.illustrated mean total score of nurses' knowledge about pneumonia on pre, post and follow up test. It was clear that there were highly statistical significance differences on post and follow up test than on pretest $(\mathrm{P}<0.001)$.
Table3.represented mean and standard deviations of nurse's practice about general nursing care on pre, post and follow up test. The table showed that there were highly statistical significance differences of mean scores of nurses practices on post and follow up test regarding all general nursing care procedures than on pretest $(\mathrm{P}<0.001)$.

Table4. represented mean and standard deviations of nurse's practice about specific nursing care for pneumonia on pre, post and follow up test. The table showed that there were highly statistical significant differences of mean score of nurses practice on post and follow up test regarding specific nursing care than on pretest $(\mathrm{P}<0.001)$.

Table 5. illlustrated mean total score of nurses' practices for pneumonia on pre, post and follows up test. It was clear that there were highly statistical significance differences between pre and posttest regarding nurse's practices $(\mathrm{P}<0.001)$.

Table6. showed distribution of studied children according to their length of hospitalization. It was found that there was a highly statistical significant difference between duration of hospitalization before starting the intervention and immediately post intervention $(\mathrm{P}<0.001)$. As well as there was a significant difference between immediate post intervention and after 3 months.

Figure1. represented Pearson correlation between total knowledge and total practice score of studied nurses regarding their protocol of care on pre, post and follow up test. The figure clarified that there were positive correlation between nurse's total knowledge and total practice scores $(\mathrm{P}<0.001)$. 


\section{Effect of A Nursing Care protocol on the Duration of Hospitalization of Children with \\ Pneumonia}

Figure 2: clarified Pearson correlation between total knowledge score of studied nurses and children length of hospitalization. It was clear that there were positive correlation between total knowledge score of studied nurses and children length of hospitalization $(\mathrm{P}<0.001)$.
Figure 3. clarified Pearson correlation between total practice scores of studied nurses and children length of hospitalization. It was clear that there were positive correlation between total practice score of studied nurses and children length of hospitalization $(\mathrm{P}<0.001)$.

Table (1): Distribution of Studied Nurses and Children According To Their Characteristics.

\begin{tabular}{|c|c|c|}
\hline Characteristics & No $(n=40)$ & $\%$ \\
\hline $\begin{array}{l}\text { Nurses age (years) } \\
\text { a. }<20 \\
\text { b. } 20-24 \\
\text { c. } 25-30 \\
\text { d. }>30\end{array}$ & $\begin{array}{l}1 \\
11 \\
18 \\
10\end{array}$ & $\begin{array}{c}2.5 \\
27.5 \\
45 \\
25\end{array}$ \\
\hline $\begin{array}{l}\text { Nurses educational level } \\
\text { a- Diploma } \\
\text { b- Technical institute } \\
\text { c- Bachelor }\end{array}$ & $\begin{array}{l}15 \\
10 \\
15\end{array}$ & $\begin{array}{l}37.5 \\
25.0 \\
37.5\end{array}$ \\
\hline $\begin{array}{l}\text { Nurses years of experience } \\
\text { a- } 1-3 \text { years } \\
\text { b- } 4-6 \text { years } \\
\text { c- } 7-9 \text { years } \\
\text { d- }>9 \text { years }\end{array}$ & $\begin{array}{c}14 \\
12 \\
3 \\
11\end{array}$ & $\begin{array}{c}35.0 \\
30.0 \\
7.5 \\
27.5\end{array}$ \\
\hline $\begin{array}{l}\text { Child age } \\
\text { a) } 66 \text { months } \\
\text { b) } 6 \mathrm{~m}-1 \text { years } \\
\text { c) } 2-5 \text { y years } \\
\text { d) } 6-10 \text { years }\end{array}$ & $\begin{array}{c}1 \\
3 \\
31 \\
5\end{array}$ & $\begin{array}{l}2.5 \\
7.5 \\
77.5 \\
12.5\end{array}$ \\
\hline $\begin{array}{ll}\text { Classification of children with pneumonia } \\
\text { a) } & \text { Not severe } \\
\text { b) Severe } \\
\text { c) } \\
\text { d) Very severe } \\
\text { Very very severe }\end{array}$ & $\begin{array}{c}0 \\
8 \\
30 \\
2\end{array}$ & $\begin{array}{c}0.0 \\
20.0 \\
75.0 \\
5.0\end{array}$ \\
\hline
\end{tabular}

Table (2): Mean Total Score of Nurses' Knowledge about Pneumonia on Pre, Post and Follow Up Test.

\begin{tabular}{|c|c|c|c|c|c|}
\hline Total score & $\begin{array}{l}\text { Pretest } \\
\qquad(n=40)\end{array}$ & $\begin{array}{r}\text { Posttest } \\
(n=40)\end{array}$ & $\begin{array}{l}\text { Follow up test } \\
\qquad(n=40)\end{array}$ & $\begin{array}{c}\text { ANOVA } \\
\text { Test }\end{array}$ & $P$-value \\
\hline Mean \pm SD & $64.07 \pm 5.97$ & $80.55 \pm 3.19$ & $77.63 \pm 3.28$ & $99.95 * *$ & 0.000 \\
\hline
\end{tabular}




\section{Effect of A Nursing Care protocol on the Duration of Hospitalization of Children with Pneumonia}

Table (3): Mean and Standard Deviations of Nurses' Practice Regarding General Nursing Care of Pneumonia on Pre, Post and Follow Up Tests.

\begin{tabular}{|c|c|c|c|c|c|}
\hline \multirow[t]{2}{*}{ Nursing procedure } & $\begin{array}{l}\text { Pretest } \\
(\mathrm{n}=40)\end{array}$ & $\begin{array}{c}\text { Posttest } \\
(\mathrm{n}=40)\end{array}$ & $\begin{array}{l}\text { Follow up test } \\
\qquad(\mathrm{n}=\mathbf{4 0})\end{array}$ & \multirow[t]{2}{*}{$\begin{array}{c}\text { ANOVA } \\
\text { test }\end{array}$} & \multirow[t]{2}{*}{ p- value } \\
\hline & Mean \pm SD & Mean \pm SD & Mean \pm SD & & \\
\hline Promote rest & $8.20 \pm 1.57$ & $13.30 \pm \mathbf{0 . 7 5}$ & $12.50 \pm 1.467$ & 173.61 & 0.000 \\
\hline Control fever & $7.00 \pm 1.04$ & $9.43 \pm 1.84$ & $9.18 \pm 1.84$ & 27.25 & 0.000 \\
\hline Hand washing & $7.23 \pm 1.19$ & $13.75 \pm 1.19$ & $12.02 \pm 1.53$ & 265.58 & 0.000 \\
\hline Mouth care & $7.33 \pm 1.94$ & $16.63 \pm 2.28$ & $14.45 \pm 1.54$ & 250.54 & 0.000 \\
\hline Oral medication & $12.00 \pm 1.82$ & $15.40 \pm 0.93$ & $14.83 \pm 1.43$ & 63.68 & 0.000 \\
\hline Intramuscular injection & $20.20 \pm 2.36$ & $26.90 \pm 1.32$ & $25.85 \pm 2.13$ & 131.8 & 0.000 \\
\hline Intravenous injection & $24.60 \pm 2.37$ & $30.40 \pm 1.78$ & $30.18 \pm 1.60$ & 114.05 & 0.000 \\
\hline Measuring temperature & $16.20 \pm 1.65$ & $21.10 \pm 1.03$ & $20.65 \pm 1.39$ & 153.89 & 0.000 \\
\hline Measuring apical pulse & $5.25 \pm .66$ & $9.65 \pm 0.66$ & $8.45 \pm \mathbf{0 . 9 0}$ & 364.08 & 0.000 \\
\hline Measuring respiration & $4.88 \pm \mathbf{0 . 9 7}$ & $6.25 \pm 1.43$ & $6.10 \pm 0.87$ & 18.30 & 0.000 \\
\hline Nasogastric feeding & $8.20 \pm 1.57$ & $13.30 \pm \mathbf{0 . 7 5}$ & $12.50 \pm 1.467$ & 173.61 & 0.000 \\
\hline Bottle feeding & $8.83 \pm 1.28$ & $13.48 \pm \mathbf{0 . 7 5}$ & $12.70 \pm 1.09$ & 219.80 & 0.000 \\
\hline Oxygen therapy & $25.40 \pm 2.77$ & $32.90 \pm 1.96$ & $31.87 \pm 2.81$ & 102.16 & 0.000 \\
\hline
\end{tabular}

Table (4): Mean and Standard Deviations of Nurses' Practice Regarding Specific Nursing Care of Pneumonia on Pre, Post and Follow Up Tests.

\begin{tabular}{|c|c|c|c|c|c|}
\hline \multirow[t]{2}{*}{ Nursing procedure } & $\begin{array}{l}\begin{array}{l}\text { Pretest } \\
(\mathrm{n}=40)\end{array} \\
\end{array}$ & $\begin{array}{c}\text { Posttest } \\
(\mathrm{n}=40)\end{array}$ & $\begin{array}{c}\text { Follow up test } \\
(n=40)\end{array}$ & \multirow[t]{2}{*}{$\begin{array}{c}\text { ANOVA } \\
\text { test }\end{array}$} & \multirow[t]{2}{*}{ p- value } \\
\hline & Mean \pm SD & Mean \pm SD & Mean \pm SD & & \\
\hline Oxygen therapy & $25.40 \pm 2.77$ & $32.90 \pm 1.96$ & $31.87 \pm 2.81$ & 102.16 & 0.000 \\
\hline Mechanical ventilation & $11.50 \pm 1.32$ & $14.45 \pm 0.88$ & $13.90 \pm 1.10$ & 79.15 & 0.000 \\
\hline Suction (Nasal - Oral) & $27.48 \pm 3.57$ & $36.10 \pm 4.63$ & $35.40 \pm 4.28$ & 52.46 & 0.000 \\
\hline Endotracheal tube suctioning & $20.05 \pm 3.30$ & $30.90 \pm 1.43$ & $28.28 \pm 1.91$ & 232.33 & 0.000 \\
\hline Postural drainage & $22.48 \pm 3.76$ & $30.38 \pm 2.11$ & $29.40 \pm 2.97$ & 81.38 & 0.000 \\
\hline Assist in diagnostic measures & $30.58 \pm 3.06$ & $41.47 \pm 1.15$ & $39.35 \pm 2.12$ & 263.57 & 0.000 \\
\hline Psychological support & $2.45 \pm 1.06$ & $4.08 \pm 1.31$ & $3.63 \pm 1.15$ & 20.33 & 0.000 \\
\hline Preparation for discharge & $5.95 \pm 1.18$ & $8.07 \pm 1.89$ & $7.77 \pm 2.01$ & 17.70 & 0.000 \\
\hline
\end{tabular}


Figure (1): Pearson Correlation between Total Knowledge and Total Practice Score of Studied Nurses

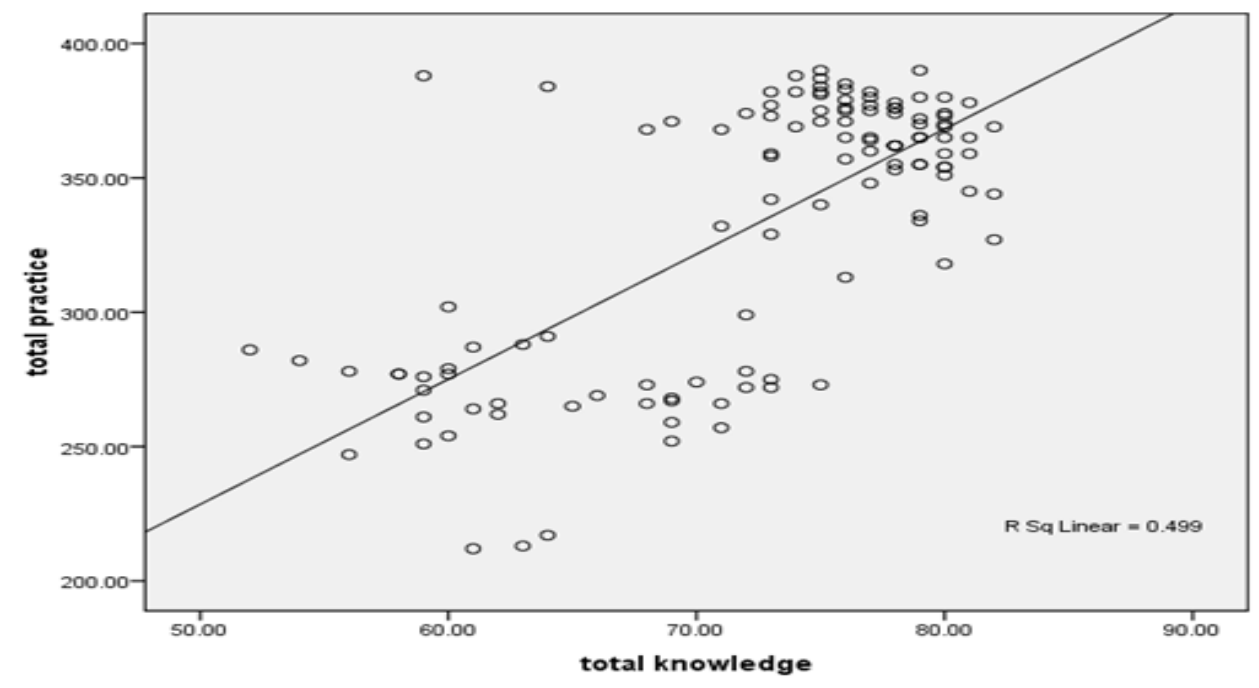

Figure (2): Pearson correlation between Total Knowledge Score of Studied Nurses and Children Length of Hospital Stay.

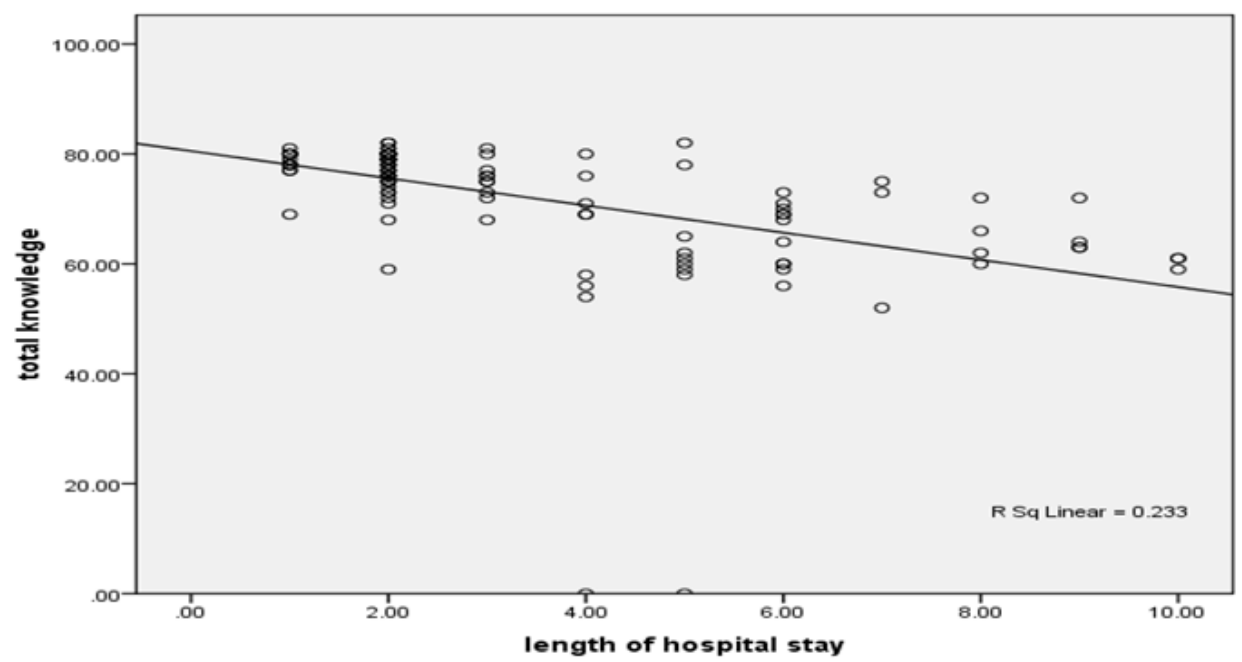

Figure (3): Pearson correlation between Total Practice Scores of Studied Nurses and Children Length of Hospital Stay.

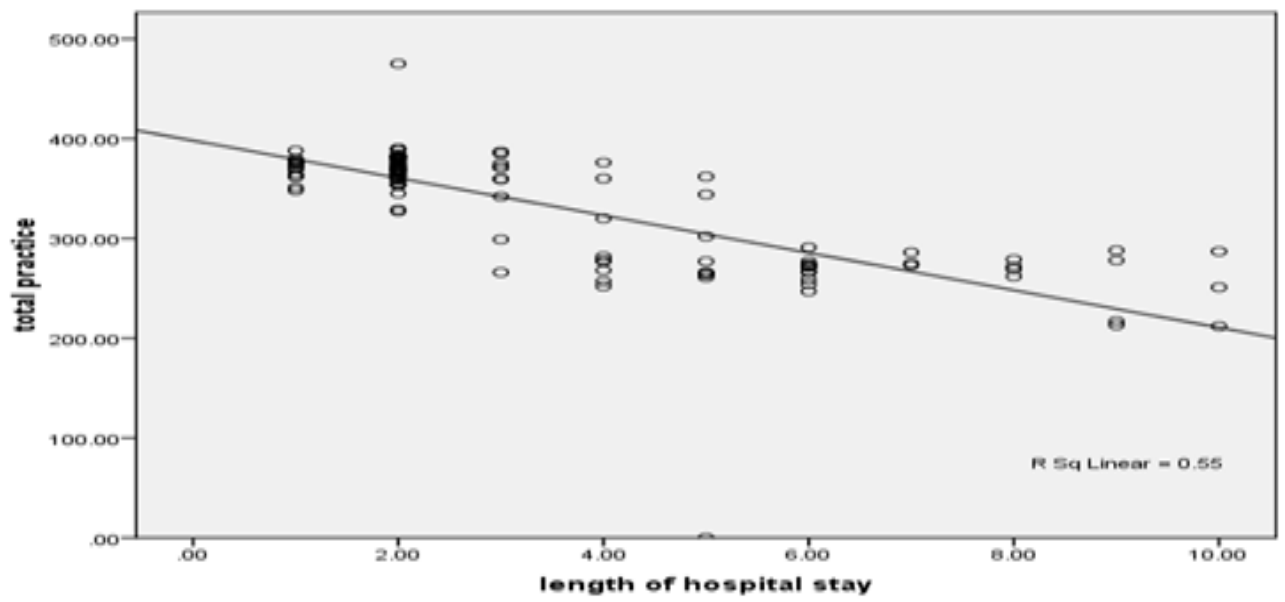




\section{Effect of A Nursing Care protocol on the Duration of Hospitalization of Children with \\ Pneumonia}

\section{Discussion}

Pneumonia causes substantial morbidity in children worldwide. The highest incidence of pneumonia is in children under five years old, American Lung Association (2012). Length of hospitalization will increase if prognosis of pneumonia is bad, Nacul et al., ( 2015). Effective nursing intervention provided to children with pneumonia will improve prognosis and decrease length of hospital stay, Grant et al., (2012). The current study hypothesized that nurses who adhered to the nursing care protocol gain more knowledge and had better practice toward children with pneumonia. Also, it hypothesized that children experienced less duration of hospitalization after implementation of the nursing care protocol.

Concerning total mean score of nurses knowledge about pneumonia it was noted that nurses had higher knowledge on posttest than on pretest. This result was consistent with Blots, et al., (2015) who conducted a study about "Evidence - Based Guidelines for Prevention of Pneumonia in Children: Result of knowledge and practice Test among Intensive Care Unit Nurses". Results reveald that the mean total scores of nurse's knowledge increased on posttest than on pretest. From the researcher point of view this could be attributed to the effectiveness of the educational methods that were used in teaching the nursing care protocol.

Regarding nurse's practice about general nursing care, the present study revealed that mean and standard deviation of nurses practice improved immediately after implementation of protocol of care than pre implementation regarding all items of general nursing care. Such finding agreed with Badway (2014) who conducted a study about "Impact of Structured Teaching Program for Prevention of Ventilator Associated Pneumonia on Knowledge and Practices of Intensive Care Unit Nurse". The results revealed that mean and standard deviation of general nursing care increased after implementation of teaching program for nurses. From the researcher perspective this could be attributed to the effectiveness of the practical sessions which given by the researcher.

Regarding nurse's practices about specific nursing care. The present study clarified that the mean and standard deviation increased on posttest than on pretest regards specific nursing care. Such result agreed with Hansson (2014) who conducted a study about "the effectiveness of education on nurse's knowledge and skills in adhering to guidelines to prevent pneumonia". The study found that mean and standard deviation of specific nursing care increased after adhering to educational guidelines. From the researcher point of view this could be attributed to nurse's compliance to the nursing care protocol.

In relation to mean total score of nurse's practices regarding care of children with pneumonia on pre, post and follow up test, the present study clarified that the studied nurses had higher mean total score on posttest than on pretest. Such a result was agreed with Badway (2014) the results revealed that the mean total score of nurse's practice increased on posttest than pretest. From the researcher point of view, this could attributed to nurse's ability to provide standardized nursing care after having the well prepared practical educational program.

Concerning distribution of children according to their length of hospital stay, the present study showed that children length of hospital stay decreased on posttest compared to pretest. Such finding was consistent with Jennifer (2016) who conducted a study about "Potentially avoidable hospitalization in institiulaized children". The findings illustrated that effective medical and nursing care for children will decrease their hospital stay. Also, such result came in line with Flores 
(2013) who conducted a study about "keeping children out of hospitals and how pediatric hospitalization can be avoided". The study concluded that after implementation of health education program for nurses, length of children hospital stay decreased.

On the other hands, this result was inconsistent with Lau et al., (2016) who conducted a study about "Pneumonia related hospitalization among children in Hong Kong". The study concluded that length of hospital stay increased with pneumonia because of bad prognosis, lack of supplies and shortage of staff training. From the researcher point of view such result could be attributed to nurse's adherence to nursing care protocol about pneumonia.

Concerning Pearson correlation between total knowledge and total practice scores of studied nurses, it was clear that there was a positive correlation between total nurse's knowledge and total nurses practice scores. Such finding agreed with Grand et al., (2012) who conducted a study about "Prevention and treatment of pneumonia: can knowledge and practice be simply assessed in a large institution." The finding concluded that there was a positive correlation between total nurse's knowledge and total nurses practice scores after adherence to training program. From the researcher perspective such finding could be attributed to the importance of continuous training program for nurses about pneumonia.

Pearson correlation was done between total knowledge score, total practice score and length of hospital stay, The present study revealed that when nurse's knowledge and practice increased, the children's length of hospital stay decreased. Such finding was consistent with Lee et al., (2014) who conducted a study about "National Hospitalization Trends for Pediatric Pneumonia and Associated Complication". The study concluded that training program for the pediatric nurses' reduced children length of hospitalization. From the researcher perspective this could reflect the importance of continuous training program for nurses' that increase their knowledge and improve their practices which in turn reduce the length of children hospital stay. These results supported the proposed hypothesis of the present study.

\section{Conclusion}

Duration of hospitalization of children with pneumonia was reduced after implementation of the nursing care protocol. Also, nurses gained more knowledge and had better practices on posttest following adherence to the nursing care protocol.

Recommendations

\section{1- Recommendations for Clinical Nursing Practice:-}

a- Newly staff members in PICU and medical word should be oriented with the standardized nursing care protocol to manage pneumonia.

b- Continuous in- service education program should be designed and implemented to motivate nursing staff to achieve high level of nursing care.

c- A standardized form of nurse's notes for documentation should be developed based on international accepted standards.

d- Resources such as articles, journals, computers and internet should be accessible in the units for staff members to develop their knowledge and practice

\section{2- Recommendations for Nursing Education:-}

Nursing care protocol for children having pneumonia should be a part of pediatric nursing curriculum and continuous nursing education.

\section{3- Recommendation for Future Nursing Research:}

Further studies in this field should be done on a larger sample to assess the effect of 
nursing care protocol on the length of hospitalization of children with pneumonia and to allow the generalization of the findings.

\section{References}

Abd El-satar, Sh. (2017).Prevalence of Pneumonia in Egyptian Children; (3) pp. 103-107.

American Lung Association (ALA). (2014).Pneumonia in Children under Five Years.http ://www.lung.org

Badawy,A. (2014): Impact of A Structured Teaching Program for Prevention of Ventilator Associated Pneumonia on Knowledge and Practices of Intensive Care Nurses at Central Quwesna Hospital, Egypt: 82(1); 803-813

Blots., Labeaus., Nandijkd. (2015): Evidence Based guidlins for Prevention of Pneumonia in Children: Results of Knowledge and practice Test Among Intensive Care Nurses: 33 (8); 1463-1467

Center for Disease Control (2014); Guidelines for preventing Health Care Associated

Pneumonia Recommendation of the CDC and the health care Infection Control Practices Advisory Committee. MMWR, 53(No.RR-3).

Flores, Gm., Chaisson, E., Suid, D. (2013) Keeping Children out of Hospitals,vol(6): 122-127.

Grand, A., Munoz, P., Rello, J., (2012).Prevention and Treatment of Pneumonia: Can Knowledge and Practice be Simply Assessed in A Large Institution, 70(2): 180.

Grant, Campbell,H.,Dowell,S.(2012):Recom mendations for Treatment of
Childhood Non Severe Pneumonia;9. P.P. $185,196$.

Hansson, $m$ (2014) : the effectiveness of education on nurses knowledge and skills in adhering to guidelines to prevent pneumonia; university of Oulu, faculty of medicine, nursing sciences; 17: 235-242

Jennifer, D. (2016): Potentially Avoidable Hospitalization in Institualized Children; 8 (6), 121-127.

Kyle, G.(2015):Recommendations for Treatment of Childhood Non Severe Pneumonia;9. P.P. 185,196.

Labeau, S., Vandijck, M. \& Claes, B., (2007). Critical care nurses' knowledge of evidence based guidelines for preventing ventilator associated pneumonia: an evaluation questionnaire. American Journal of Critical Care; 16(4), pp. 371 - 377.

Lau, Y., Chan, K.,Peris, J.(2016) : Pneumonia Related Hospitalizations Among Children in Hong Kong, PP.1$17,50-57$.

Nacul, L., Kirkwood, B., Carneir,A. (2015).Etiology and Clinical Presentation of Pneumonia in Hospitalized and Out Patients Children in North East Brazil; 25: 615.

Rylance, M. (2016).Pneumonia in children under five years old, Nursing Science (6), 767-776.

Suliadi, K., Drover, W., Montgomery, H. (2017).Candian Clinical Practice Guidelines for Nutrition Support in Critically Ill Children; 27(5):355-373. Retrieved from http: www.Ceacco Oxford Journals.Org

World Health Organization (2014); Handbook of IMCI (Integrated Management of Childhood Illness). 